\title{
Article \\ A Comprehensive Commercialization Framework for Nanocomposites Utilizing a Model-Based Systems Engineering Approach
}

\author{
Sebastian Kirmse *,t(D), Robert J. Cloutier $(\mathbb{D}$ and Kuang-Ting Hsiao *(D) \\ College of Engineering, University of South Alabama, Mobile, AL 36688, USA; rcloutier@southalabama.edu \\ * Correspondence: kirmse.sebastian@gmail.com (S.K.); kthsiao@southalabama.edu (K.-T.H.) \\ + Current Affiliation: MHP Americas, Inc., Atlanta, GA 30354, USA.
}

Citation: Kirmse, S.; Cloutier, R.J.;

Hsiao, K.-T. A Comprehensive

Commercialization Framework for

Nanocomposites Utilizing a

Model-Based Systems Engineering

Approach. Systems 2021, 9, 84.

https://doi.org/10.3390/

systems 9040084

Academic Editor: William T. Scherer

Received: 8 October 2021

Accepted: 13 November 2021

Published: 23 November 2021

Publisher's Note: MDPI stays neutral with regard to jurisdictional claims in published maps and institutional affiliations.

Copyright: (c) 2021 by the authors. Licensee MDPI, Basel, Switzerland. This article is an open access article distributed under the terms and conditions of the Creative Commons Attribution (CC BY) license (https:// creativecommons.org/licenses/by/ $4.0 /)$.

\begin{abstract}
Nanocomposites provide outstanding benefits and possibilities compared to traditional composites but struggle to make it into the market due to the complexity and large number of associated challenges involved in, as well as lack of standards for, nanocomposite commercialization. This article proposes a commercialization framework utilizing market analysis and systems engineering to support the commercialization process of such high technologies. The article demonstrates the importance and usefulness of utilizing Model-Based Systems Engineering throughout the commercialization process of nanocomposite technologies when combining it with the Lean LaunchPad approach and an engineering analysis. The framework was validated using a qualitative research method with a case study approach. Applying this framework to a nanocomposite, called ZT-CFRP technology, showed tremendous impacts on the commercialization process, such as reduced market and technological uncertainties, which limits the commercialization risk and increases the chance for capital funding. Furthermore, utilizing the framework helped to decrease the commercialization time and cost due to the use of a lean engineering analysis. This framework is intended to assist advanced material-based companies, material scientists, researchers and entrepreneurs in academia and the industry during the commercialization process by minimizing uncertainties and risks, while focusing resources to reduce time-to-market and development costs.
\end{abstract}

Keywords: Model-Based Systems Engineering (MBSE); systems thinking; business model canvas (BMC); nanocomposites; commercialization; product development

\section{Introduction}

\subsection{The Complexity of Commercializing Nanocomposites}

With the constantly growing needs and expectations of our society, material scientists are continuously trying to improve the design and performance of products and systems. For the past decade, nanocomposites (Nanocomposites are multiphase materials that consist of at least one nano-scale phase, e.g., nanoparticles or nanofillers) have shown promising results in terms of overcoming the limitations of traditional composites (e.g., fiber-reinforced polymer (FRP) composites), which could further expand the application range of such materials.

For example, carbon fiber-reinforced polymer (CFRP) laminates, which are often a preferred material over metals due to their high strength-to-weight ratio, are used in industries (Examples of such industries are the aerospace, wind turbine, automotive, and sporting goods industry) where weight-savings and high performance are of critical importance. However, traditional CFRP laminates are prone to matrix-dominated damages (Matrixdominated properties are mainly compressive failure, delamination, and shear failure.) [1] and have a low through-thickness conductivity due to their multi-ply structure [2]. These drawbacks limit the potential application uses of the material. Therefore, researchers are performing various research studies to overcome those weaknesses [3]. The use of 
nanofillers, e.g., carbon nanotubes (CNTs), carbon nanofibers (CNFs), carbon black (CB), and graphene have shown promising results in terms of increasing the material properties, e.g., mechanical, thermal and electrical, of CFRPs [4].

These promising results, in terms of the material properties that nanocomposites show, could push the boundaries of products and systems. However, their commercialization is currently limited due to numerous challenges in production, quality control, and marketing. Moreover, as discussed by Kordas [5], three main challenges hinder the commercialization of translational materials (e.g., nanocomposites): (1) the gap between academia and the industry in terms of strategic collaborations and information exchange; (2) the need for funding from funding agencies to bridge the gap between innovations and practical applications; and (3) the necessity of considering sustainability, including energy efficiency, when developing advanced materials. With the currently available methods and strategies, and due to the lack of knowledge related to the successful commercialization of nanocomposites, those technologies usually do not advance out of the development phase and never make it into the industry. Therefore, additional knowledge and new approaches are needed to shorten the commercialization time, cost and risk, and to ease the way towards the commercialization of nanocomposites. Additional research is required to increase the knowledge about individual nanocomposite properties and market uncertainties, and to improve the understanding of what parameters drive a successful nanocomposite commercialization process. This will require a holistic approach. Holistic thinking, which is an integral part of the systems engineering approach, will be more important than ever for commercializing nanocomposites.

This manuscript presents a newly proposed framework to support the commercialization of high technologies by not just reducing market uncertainties, but also technological uncertainties, to limit the commercialization risk and increases the chance for capital funding. The following sections provide a description of the proposed framework, including its scope and limitations, together with a validation based on a case study.

Sub-Section 1.2 provides background information regarding the development of the framework. Section 2 includes a description of the framework development methodology. Sections 3 and 4 include a description of the framework, its validation, as well as limitations and additional discussions. The last section provides a summary of the results and findings together with future work suggestions.

\subsection{The ZT-CFRP Technology and the National NSF I-Corps Teams Program}

One example of such a nanocomposite technology that is currently on the verge of commercialization is the ZT-CFRP technology developed by Hsiao's Research Group at the University of South Alabama [6]. The ZT-CFRP technology is a CFRP laminate reinforced with CNF z-threads, which improve the material's mechanical, electrical and thermal properties [7-11]. This nanocomposite technology just reached the so-called technological 'valley of death' in terms of investment/funding opportunities (see Figure 1). 


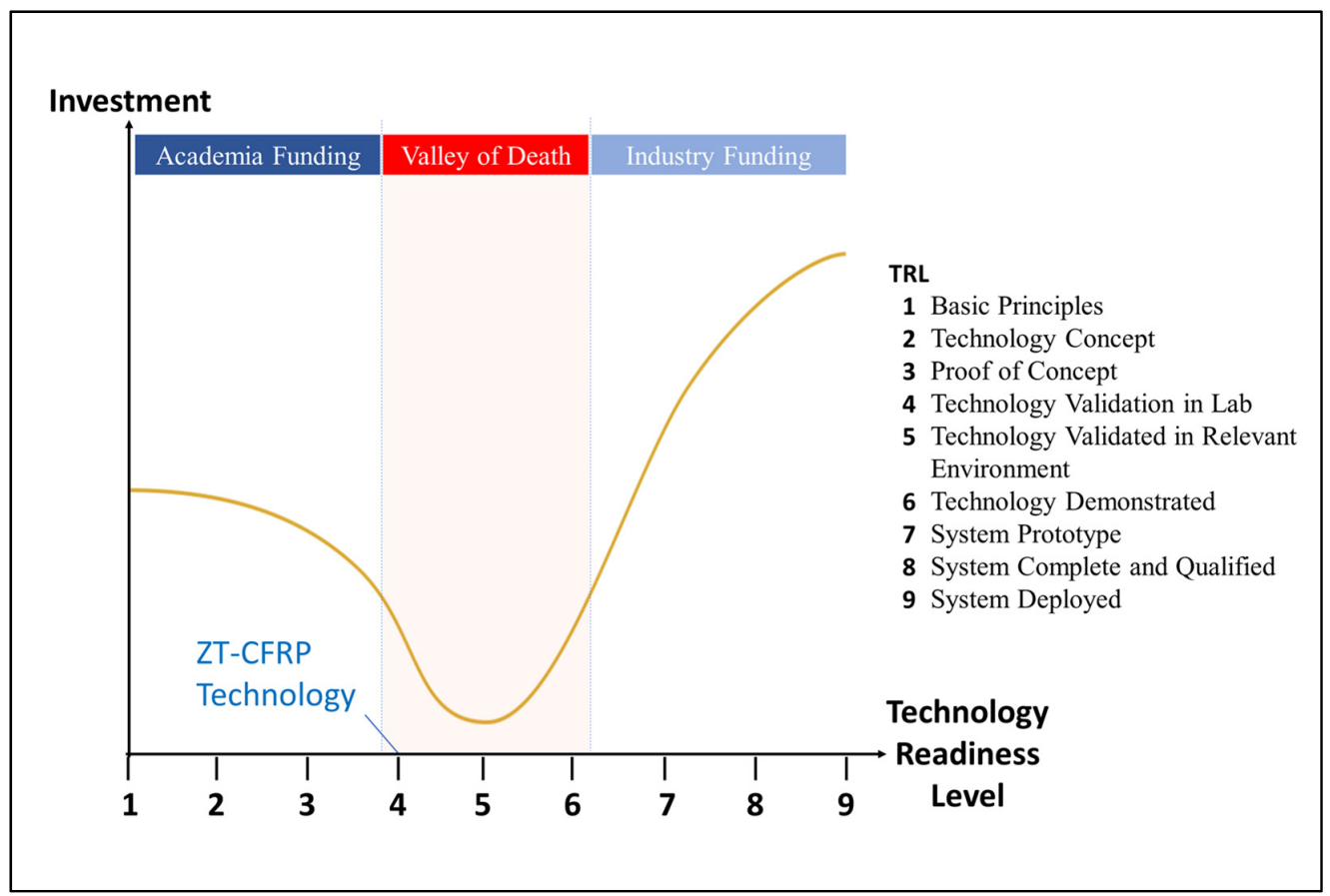

Figure 1. Investment vs. technology readiness level (TRL), showing the technological 'valley of death'. (Significantly modified and redrawn from the original by Rossini [12], Figure 1 is a generalized and static view of the investment/funding opportunity curve and might be more dynamic depending on the technology.).

The 'valley of death' is the gap between academic research and industrial commercialization [11]. A technology usually falls into this investment gap due to the technology's maturity level, i.e., its technology readiness level (TRL) [13]. At this point, the technology is too mature for academic research funding; meaning it is not considered as fundamental research anymore, which is a requirement for academic research funding. However, the technology is not mature enough for industrial commercialization funding due to too many uncertainties and the large risks involved for successful commercialization. Many potential breakthrough ideas do not make it through this 'valley of death', and therefore, never transition from laboratory research into societal applications. For this reason, the National Science Foundation (NSF) developed a new funding opportunity, called the NSF Innovation Corps (I-Corps) Program [14]. The program is designed to help NSF-funded, basic research to bridge this gap and move technologies towards commercialization by reducing market uncertainties through the use of the Lean LaunchPad approach that was developed by Steve Blank [15].

The authors (Kirmse and Hsiao) went through the National NSF I-Corps Teams Program to perform a rigorous customer discovery process and to determine the commercialization potential of the ZT-CFRP technology. The performed customer discovery process, which was continued even after successful completion of the I-Corps program, involved over 120 interviews with industry experts within the aerospace, automotive, sporting goods and other composite-using industries in Europe (e.g., Germany and France) and throughout the United States. The program incorporates the Lean LaunchPad approach, which is a precursor of the well-known Lean Startup method (LSM) [16]. Using this approach, a commercialization strategy is developed and summarized on one page, called the Business Model Canvas, with the value propositions being the 'heart' of the whole commercialization strategy. Harms et al. [17] state that the LSM has excellent benefits when addressing market uncertainties. However, since advanced-material ventures also face high technological uncertainties [18], the LSM lacks additional features and requires significant customization to accommodate the networking component, which is essential during the commercialization process of nanotechnologies [18]. This research discovered 
similar limitations when applying the Lean LaunchPad approach to develop a commercialization strategy for the ZT-CFRP technology. Both market uncertainties and technological uncertainties have to be eliminated to produce a strong commercialization strategy with a high possibility for success. Furthermore, during the customer discovery process, the researchers discovered that even if a potentially strong commercialization strategy is developed, potential customers have to be convinced of the claimed value propositions. While nanocomposites were first introduced over a decade ago, they were overly hyped up due to their large potential. Due to dispersion and other issues, the technology struggled to live up to the hype, leaving potential customers disappointed. Therefore, relevant and meaningful material data have to be provided for the potential customers for them to consider testing this novel nanocomposite. Moreover, commercializing a new technology is very complex due to the involvement of many stakeholders and requires interaction between many different entities with different backgrounds. In many situations, while the engineering performance of the new materials is important, there are other factors the individual stakeholders consider as well.

Systems Engineering allows one to view these commercialization challenges from multiple perspectives. It helps to analyze the stakeholders' inputs and behaviors in the system. Moreover, it provides the necessary tools and methodologies to identify individual connections between entities and other variables and, therefore, helps to identify the complexity of the overall problem and challenges [19]. One of those methodologies is Model-Based Systems Engineering (MBSE), which is a model-centric approach (as opposed to a document-centric approach). It helps to improve communication between stakeholders due to the visual support from the models. Furthermore, MBSE provides the capability to look at all aspects of the technology in terms of structure, behavior, requirements, and parametrics via the creation of a comprehensive high-level architecture model. [20,21]

The objectives of this study were to develop a commercialization support solution that helps not just with market uncertainties, but also with technological uncertainties. The framework needed to be superior to a traditional commercialization approach such as the Lean LaunchPad.

The researchers propose a framework in which MBSE plays an important role when trying to overcome the many market-and especially technological-uncertainties that arise during the commercialization of nanocomposites. Additionally, the authors further propose that this framework is a combination of the Lean LaunchPad approach, a ModelBased Systems Engineering methodology and a thorough engineering analysis, which would tremendously support the commercialization process of nanocomposites such as the ZT-CFRP technology, and therefore, shorten the time to market, reduce costs and limit the risks.

The proposed framework was developed and based on a case study for the ZT-CFRP technology. It was validated using a qualitative validation approach and the results of the case study. Part of the validation process was a qualitative comparison between the Lean LaunchPad approach and the proposed framework, with the focus on different factors such as the reduction in uncertainties as well as the likelihood of receiving funding. Moreover, other validation criteria, such as the effects and usefulness of this framework, were determined by comparing the commercialization status and technical readiness level (TRL) before and after utilizing the framework during the commercialization process of the ZT-CFRP technology.

The following section provides the methodology used for the development of the proposed framework, followed by the results and discussion sections.

\section{Methodology}

A qualitative research method in terms of a case study approach was used for the development and evaluation of the proposed commercialization framework. Such a method can be useful to study an issue or problem in its natural environment by allowing researchers to understand the issue or problem deeply with the help of real-life conditions [22]. The 
effects and usefulness of the framework are based on empirical studies of a nanocomposite technology, called ZT-CFRP technology.

The framework consists of three different analyses: a market analysis, a systems analysis, and an engineering analysis. The Lean LaunchPad Approach, developed by Steve Blank [15], and a Model-Based Systems Engineering (MBSE) methodology were used for the market and systems analysis, respectively, to reduce/eliminate the market and technological uncertainties of the ZT-CFRP technology. The engineering analysis consisted of research studies that evaluate the material properties (i.e., interlaminar shear strength and compressive strength) of the ZT-CFRP nanocomposite, which are crucial elements for the commercialization process of the ZT-CFRP technology [7-10,23].

\subsection{Market Analysis Overview (i.e., the Lean LaunchPad Approach)}

The Lean LaunchPad approach is a rigorous customer discovery process used to create a viable business model, which will be represented on a business model canvas (BMC). The BMC consists of nine building blocks that connect with one another, which forms a commercialization strategy [24].

The main focus lies on the customer segmentation and the value propositions for the individual customer segments, where the value propositions are the heart of the BMC. Without a strong value proposition(s), the new venture will have a low survival rate.

Other building blocks for the BMC are: Channels, Customer Relationships, Revenue Streams, Key Resources, Key Activities, Key Partnerships and Cost Structure. More information about the process can be found in the books Value Proposition Design by Osterwalder et al. [25], Business Model Generation by Osterwalder and Pigneur [24] and The Startup Owner's Manual by Blank and Dorf [26].

The Lean LaunchPad approach helps to identify the market size and structure of the market's ecosystem, find potential customers and partnerships within the market, find viable value propositions and determine the demand creation budget and forecast as well as the customer acquisition cost, customer lifetime value, a revenue model strategy and pricing tactics.

\subsection{Systems Analysis Overview (i.e., a Model-Based Systems Engineering Methodology)}

As defined by the International Council on Systems Engineering [27]:

"Model-based systems engineering (MBSE) is the formalized application of modeling to support system requirements, design, analysis, verification and validation activities beginning in the conceptual design phase and continuing throughout development and later life cycle phases." (p. 15)

MBSE includes, for example, system architecture, behavioral analysis, performance analysis, simulation, requirement traceability, and testing. Models can help derive a consistent specification, as well as automating, analyzing and interrogating the system design. Furthermore, modeling is needed to improve communication across all stakeholders. Lately, MBSE tools have been expanded to bridge the gap between SysML (systems modeling language) and multidisciplinary analysis [20].

Weilkiens et al. [28] discuss the many benefits of MBSE, such as shorter system development times, increased customer satisfaction, reduced production costs due to less redesign, and better communication between development teams. According to Weilkiens, "If done right, systems architecture can be fun for all involved stakeholders." (p. 14)

As summarized by INCOSE UK [21], MBSE has many goals and benefits. For example, utilizing MBSE can help with communication across engineering teams and between stakeholders, and even reduce spoken language barriers. Moreover, MBSE decreases risk while enhancing the overall quality and productivity. For example, it is possible to reduce costly errors and rework due to early testing through simulation during early stages of the product development process. In addition, mapping physical to logical and functional architecture all the way to the requirements ensures rigorous traceability for improved validation and verification, and allows for advanced impact and trade-off analyses. Lastly, 
MBSE can reduce overall development time through design automation and the reuse of existing developments.

Since SysML is a notation (i.e., a collection of related and integrated diagrams), there is no standard methodology. Therefore, it is up to the systems engineer/architect to determine the best utilization of SysML and to develop a methodology that best fits the architect's needs. The MBSE methodology used by the researchers is summarized in a simplified version in Figure 2 [29]. This methodology is not a complete process, but it gives a good understanding of the modeling methodology to capture a system or even a system of systems (SoS) architecture. Following this methodology results in a comprehensive high-level architecture model that follows the first steps (i.e., the concept of operation and stakeholder requirement definition, and the system requirement and architecture definition) on the left-hand side of the systems engineering V-Model, while capturing the definition of the system in the form of requirements, behavior, structure, and parametric information (i.e., the four pillars of SysML). This methodology helps to "provide a rigorous basis of data and information for technical understanding in order to aid decision making across the life cycle" [30] of the ZT-CFRP technology.

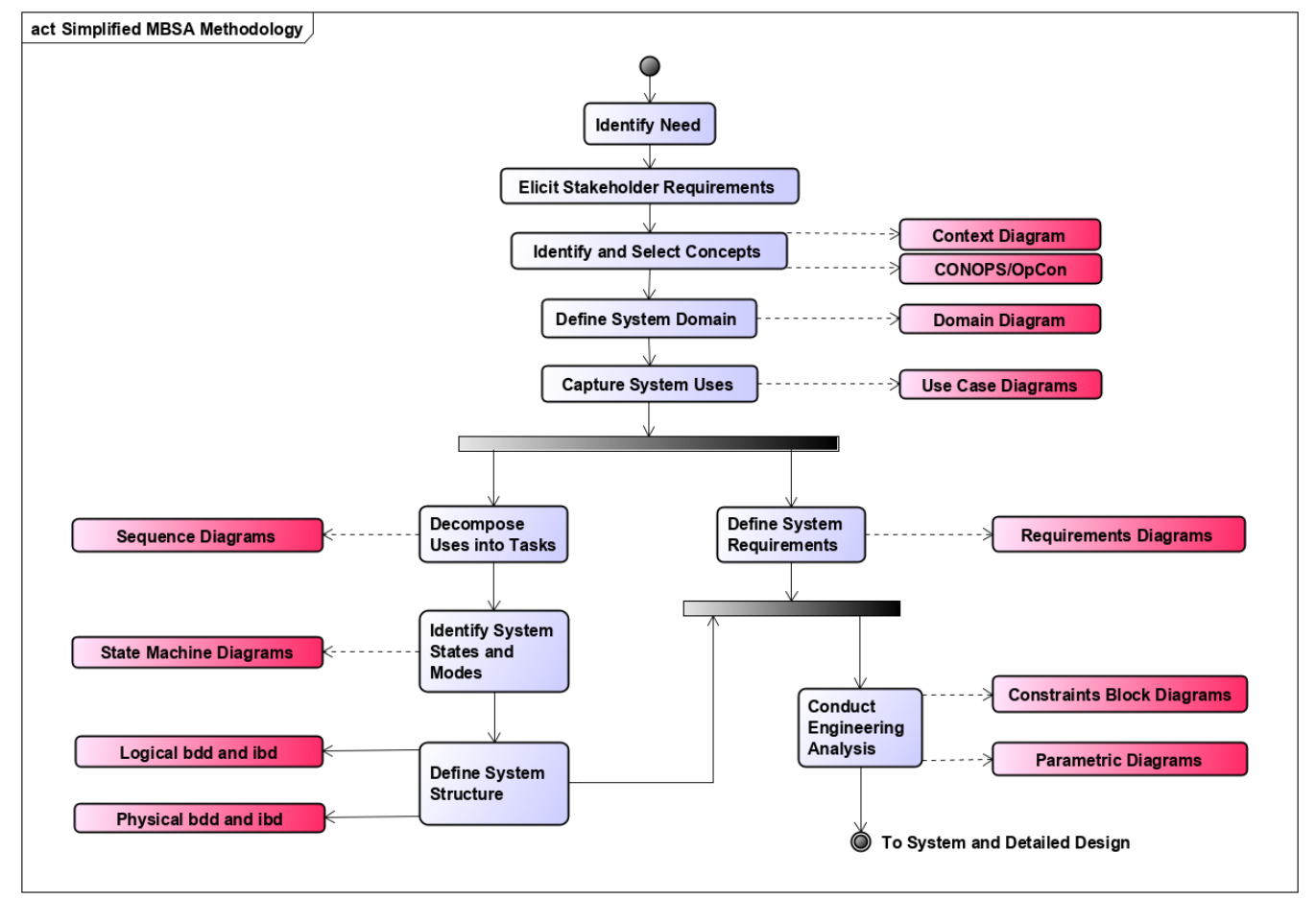

Figure 2. Overview of a simplified model-based systems architecture (MBSA) methodology, where CONOPS stands for concept of operations, bdd stands for block definition diagram, and ibd stands for internal block diagram [29].

The approach can also be described as follows [29]:

1. Defining requirements.

2. From requirements, requirements diagrams are created.

3. Requirements are further described by use cases.

4. Each Use Case is further specified using activity diagrams.

5. Requirements, use cases and activity diagrams are used to build block definition diagrams (bdds).

6. Moving from black-box to white-box views, blocks from bdds are decomposed to internal block diagrams (ibds).

7. Requirement diagrams, bdds and ibds can be used to define constraints/performance parametric diagrams.

8. Bdds, ibds, and use case models are used as the basis of Scenario Sequence Diagrams. 
9. Ibds and activity diagrams can be used as the basis of Interaction State Diagrams.

10. In summary, this MBSE methodology helps to determine the stakeholders and their requirements, the system domain, the system requirements, as well as behavioral, structural (e.g., logical and physical) and parametrical information of the technology.

\subsection{Engineering Analysis Overview}

During the customer discovery process, consisting of over 120 interviews, it was discovered that even if a potentially strong commercialization strategy is developed, potential customers have to be convinced of the claimed value propositions. Relevant and meaningful material data have to be provided for the potential customers to even consider testing the novel nanocomposite. For this, an engineering analysis is needed that focuses on the material properties and performance aspects that are most relevant to the potential customers. Therefore, the engineering analysis is driven by the market and systems analysis.

Through the customer discovery process and interviews with potential customers for the ZT-CFRP technology, it was found that matrix-dominated properties (i.e., interlaminar shear strength and compressive strength) are the main properties that potential customers in the industry are interested in. The engineering analysis for the ZT-CFRP technology consisted of three research studies that were focused on developing a better understanding of these matrix-dominated properties and their failure behavior.

The first research study [10] analyzed the interlaminar shear properties and fracture behavior of the CFRP laminates containing CNF z-threads. The second research study [23] evaluated the longitudinal compressive strength of ZT-CFRP laminates and the failure behavior during compressive loading. During the customer discovery process, the strong need for weight-savings and multi-functional composites was identified. Thus, the third research study [31] evaluated a porous ZT-CFRP composite that contained CNF z-threads and had a very low resin content. For this third research study, it was hypothesized that the CNF z-threads provide structural stability to an otherwise weak porous composite. The three peer-reviewed papers were used to support and validate the value proposition claims as developed in the market analysis, and therefore, to gain the interest of potential customers.

\section{Results}

Based on the described methodology, a commercialization framework was developed, which is descripted and validated in this section.

\subsection{The Proposed Commercialization Framework}

Figure 3 shows an overview of the proposed commercialization framework for the ZT-CFRP technology. The diagram indicates how complex the commercialization process of nanocomposites is due to the multiple key drivers, which are all interconnected with one another.

Figure 4 shows this framework outlined in a V-Model to visualize the timeline of the proposed commercialization process. The proposed framework creates a strong commercialization strategy, which consists of a combination of a market, systems and engineering analysis. For the market analysis and systems analysis, the Lean LaunchPad approach and an MBSE methodology are used, respectively, which help to eliminate most of the commercialization uncertainties. 


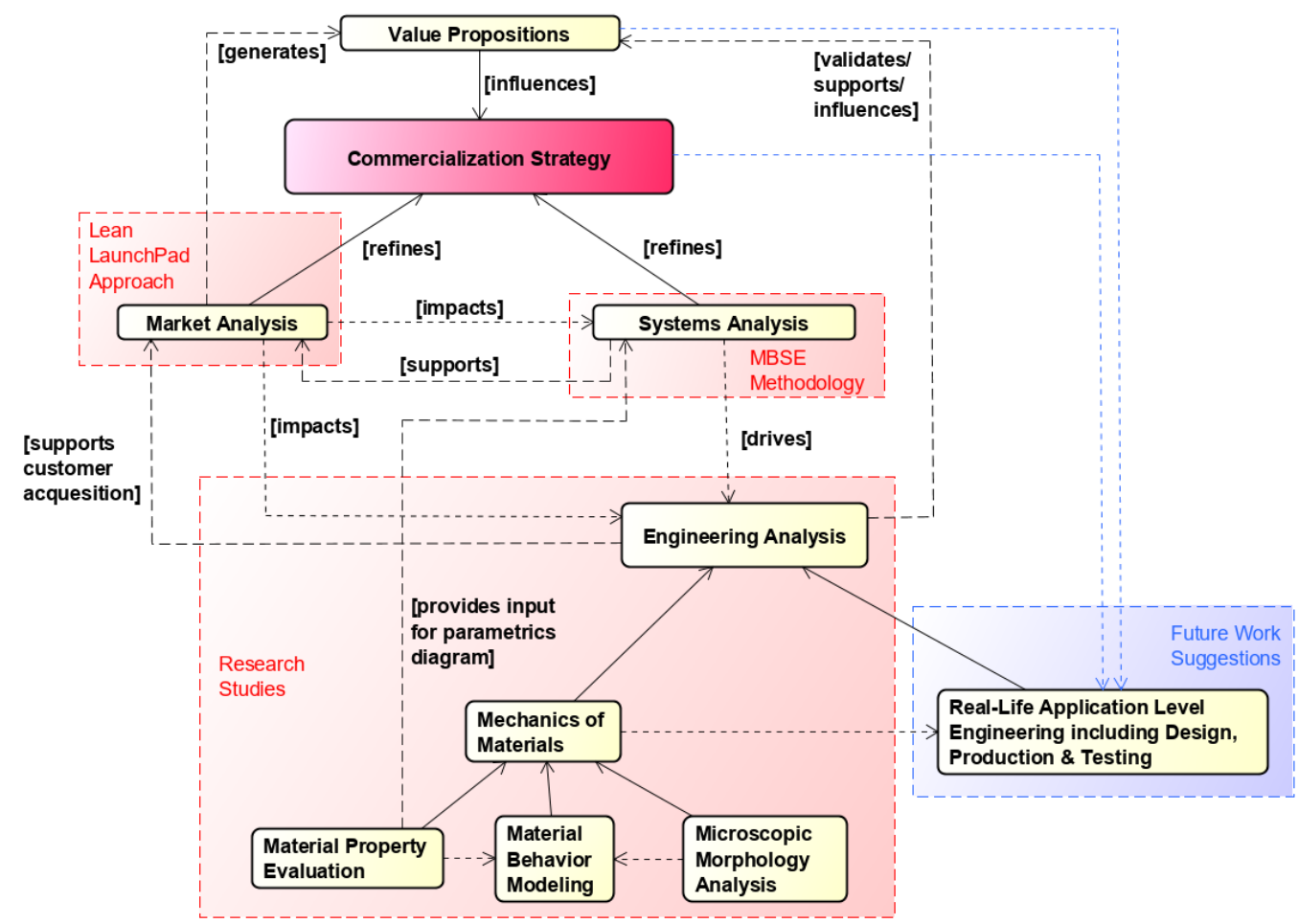

Figure 3. Proposed commercialization framework for nanocomposites such as the ZT-CFRP technology.

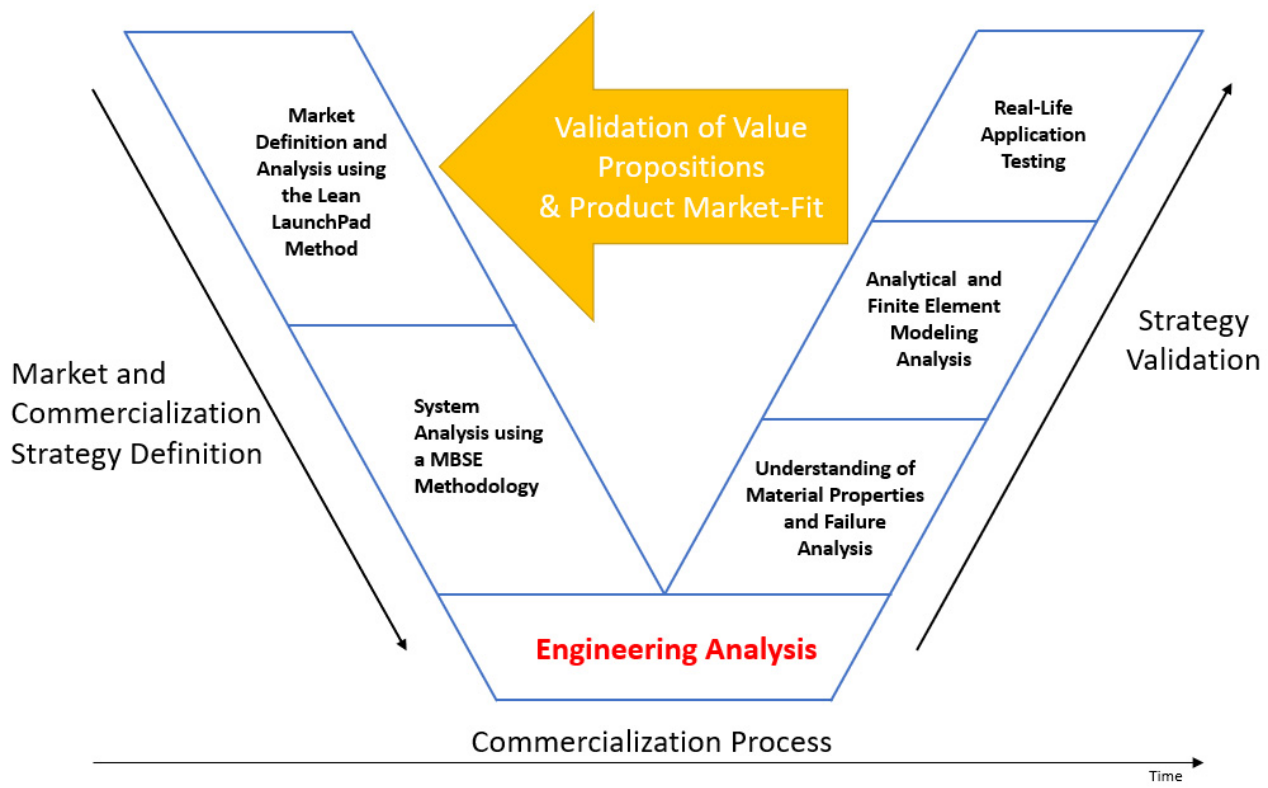

Figure 4. Proposed V-Model for the commercialization process of the ZT-CFRP technology.

Examples of the market analysis are target market size, market ecosystem, potential partnerships, direct and indirect competition, pricing tactics, startup and operation costs, marketing channels, demand creation, budget and forecast, customer acquisition costs, customer lifetime value and revenue model strategy. How to perform those individual analyses is common knowledge and is, therefore, not discussed in further detail within this paper. The detailed analysis results can be found in the dissertation written by Kirmse [32]. A sample interview questionnaire and a summary of results for individual groups of stakeholders are included in Appendices A and B, respectively. The focus in terms of specific interviewee types was mainly decision makers and influencers for material choices 
and the designers of composite product manufacturing processes, all the way to end users. Job titles of interviewees included, e.g., product designer/engineer, VP of research and development, materials engineer/scientist, $\mathrm{CEO} / \mathrm{CTO} /$ president (of smaller composite product manufacturers), R\&D development engineer, and VP of engineering.

For the systems analysis, the scope of the system analyzed in this paper is summarized in a concept of operation (CONOPS) in Appendix C. In the same appendix section, a context diagram with a focus on the golf shaft industry (since this will be the entry market) together with a system domain and stakeholder diagram is provided. Other results of the system analysis are, for example, use case diagrams, activity diagrams, requirement decomposition diagrams, requirement traceability diagrams, parametric and constraint definition diagrams, as well as an outline of the logical and physical architecture of the system, including block definition diagrams, interface diagrams and allocation diagrams. The full systems analysis results can also be found in the dissertation written by Kirmse [32].

The combination of the market and systems analysis results in a commercialization strategy with a good chance of success due to reduced market and technology risks. However, for nanocomposites, such as the ZT-CFRP technology, potential customers required additional convincing to even try the new material due to unfruitful tries of nanocomposites in the past. An extensive engineering analysis, made up of research studies $[10,23,31]$ that are driven by results of the market and systems analysis, are used to support the commercialization process by validating the value propositions to convince potential customers. The customer discovery process of the market analysis also provides the necessary information to perform a lean engineering analysis by narrowing down the testing focus and, therefore, saving resources. The engineering data support the customer acquisition (i.e., 'get, keep, and grow' process), as well as validating, supporting and influencing the value propositions. Furthermore, the engineering testing data from the engineering analysis now form the inputs for the parametric diagrams for the MBSE analysis. This shows that the proposed framework should be seen as an iterative and dynamic process.

\subsection{Framework Validation}

The presented study employed a qualitative research method using a case study approach to validate the authors' propositions and the developed commercialization framework, as mentioned in sub-Section 1.2.

Table 1 shows a comparison between the commercialization status of the ZT-CFRP technology before and after applying the framework.

By following the proposed commercialization framework, it was possible to create a strong commercialization strategy with supported value propositions for the ZT-CFRP technology. The golf shaft market segment was identified as a promising market, and it was determined that potential customers would be much more willing to test the new technology due to the extensive material data. The interviews with potential customers helped to align the testing focus for the engineering analysis. With such a lean engineering analysis, resources could be saved since only the most necessary material tests were performed. This means that instead of testing all material properties, the focus was placed on the properties in which potential customers were considered to be interested. Furthermore, the interviews helped to identify and create connections and partnerships with suppliers that are part of the golf shaft market segment's ecosystem. The results are that future tests can be performed with the relevant materials (i.e., carbon fibers and resin systems) that potential customers are currently using for their products.

These efforts improved the TRL ranking from 4 to $\sim 5$ (see Figure 5), with the probability of advancing to TRL 6 and 7 after potential customers have tested the technology and created prototypes from this new material. In addition, the technology has now reached an ideal level of maturity to receive funding through PFI (Partnership for Innovation), STTR (Small Business Technology Transfer), or SBIR (Small Business Innovation Research), etc., to help bridge the 'valley of death' towards industrial investments. 
Table 1. Overview of the current technology/commercialization status of the ZT-CFRP technology.

\begin{tabular}{|c|c|c|}
\hline Description & Initial Commercialization Status & Commercialization Status after Framework Utilization \\
\hline Tested Material Properties & $\begin{array}{ll}\text { - } & \text { Mode-I Delamination [33] } \\
\text { - } & \text { Through-Thickness DC } \\
\text { Electrical Conductivity [11,34] } \\
\text { - Through-Thickness Thermal } \\
\text { Conductivity [8] }\end{array}$ & $\begin{array}{ll}\text { - } & \text { Mode-I Delamination [33] } \\
\text { - } & \text { Through-Thickness DC Electrical Conductivity [11,34] } \\
\text { - } & \text { Through-Thickness Thermal Conductivity [8] } \\
\text { - } & \text { ILSS [10] } \\
\text { - } & \text { Compressive Strength [23] } \\
\text { - } & \text { Porous Nanocomposite [31] }\end{array}$ \\
\hline Tested CNF Concentration & $\begin{array}{ll}- & 0.1 \mathrm{wt} \% \\
& 1.0 \mathrm{wt} \%\end{array}$ & $\begin{array}{ll}- & 0.1 \mathrm{wt} \% \\
- & 0.5 \mathrm{wt} \% \\
- & 1.0 \mathrm{wt} \%\end{array}$ \\
\hline Testing Focus & All material properties & $\begin{array}{l}\text { Matrix-dominated properties (e.g., ILSS and compressive } \\
\text { strength) based on needs of the sporting goods industry }\end{array}$ \\
\hline Models & $\begin{array}{l}\text { - } \quad \text { Unicell Model [35] } \\
\text { Analytical Model of } \\
\text { Through-Thickness } \\
\text { Thermal Conductivity [8] }\end{array}$ & $\begin{array}{ll}\text { - } & \text { Unicell Model [35] } \\
\text { - } & \text { Analytical Model of Through-Thickness } \\
& \text { Thermal Conductivity [8] } \\
\text { - } & \text { Analytical Model of ILSS [10] } \\
\text { - } & \text { Supporting Model for Compressive Strength [36] } \\
\text { - } & \text { MBSE Model }\end{array}$ \\
\hline $\begin{array}{l}\text { Understanding of } \\
\text { Failure Behavior }\end{array}$ & Low & High \\
\hline Production Capabilities & $\begin{array}{l}\text { Low } \\
\text { Production Volume: } 10 \times 10 \\
\text { in. } /(2 \text { days }) \text { of prepreg } \\
\text { Prepreg Size: } 10 \times 10 \mathrm{in} .\end{array}$ & $\begin{array}{l}\text { Medium } \\
\text { Production Volume: } 20 \times 20 \text { in./day of prepreg } \\
\text { Prepreg Size: } 20 \times 20 \text { in. }\end{array}$ \\
\hline $\begin{array}{l}\text { Potential Customer's } \\
\text { Willingness to Try } \\
\text { This Technology }\end{array}$ & $\begin{array}{l}\text { Low } \\
\text { Reason: Not enough material data } \\
\text { available; low production volume; } \\
\text { prepreg size too small. }\end{array}$ & $\begin{array}{c}\text { High } \\
\underline{\text { Reason: Potential customers see great potential due to data }} \\
\text { for material property improvements. }\end{array}$ \\
\hline Market Analysis & $\mathrm{N} / \mathrm{A}$ & Yes \\
\hline Systems Analysis & $\mathrm{N} / \mathrm{A}$ & Yes \\
\hline TRL & 4 & $\sim 5$ \\
\hline $\begin{array}{l}\text { Market Focus and } \\
\text { Confidence Level }\end{array}$ & $\begin{array}{l}\text { Focus: Aerospace Industry; } \\
\text { Confidence Level: High; } \\
\frac{\text { Support for Confidence Level: }}{\text { Initial aerospace funding }}\end{array}$ & $\begin{array}{l}\frac{\text { Focus: Golf Shaft Industry; }}{\text { Confidence Level: High; }} \\
\text { Support for Confidence Level: Material data and interviews } \\
\text { with potential customers }\end{array}$ \\
\hline Commercialization Strategy & $\mathrm{N} / \mathrm{A}$ & Yes \\
\hline Funding Opportunities & $\begin{array}{l}\text { Low } \\
\text { Reason: Not fundamental research } \\
\text { anymore, but not mature enough } \\
\text { for PFI or STTR/SBIR funding. }\end{array}$ & $\begin{array}{l}\text { High } \\
\text { Reason: Ideal level of maturity for PFI or } \\
\text { STTR/SBIR funding. }\end{array}$ \\
\hline Commercialization Risk & High & Medium/Low \\
\hline $\begin{array}{l}\text { Customer Acquisition } \\
\text { Strategy }\end{array}$ & $\mathrm{N} / \mathrm{A}$ & $\begin{array}{c}\text { Publications, white papers, presentations, and } \\
\text { material testing }\end{array}$ \\
\hline Supply Chain & $\mathrm{N} / \mathrm{A}$ & $\begin{array}{l}\text { Yes } \\
\text { Based on potential customers in the sporting goods industry }\end{array}$ \\
\hline
\end{tabular}


Table 1. Cont.

\begin{tabular}{|c|c|c|}
\hline Description & Initial Commercialization Status & Commercialization Status after Framework Utilization \\
\hline IP Security & 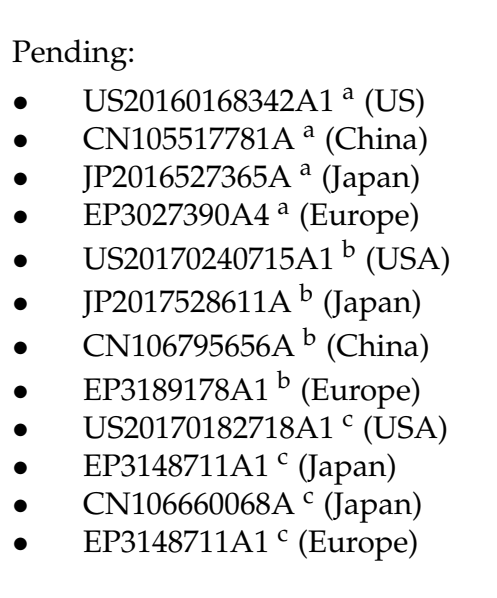 & 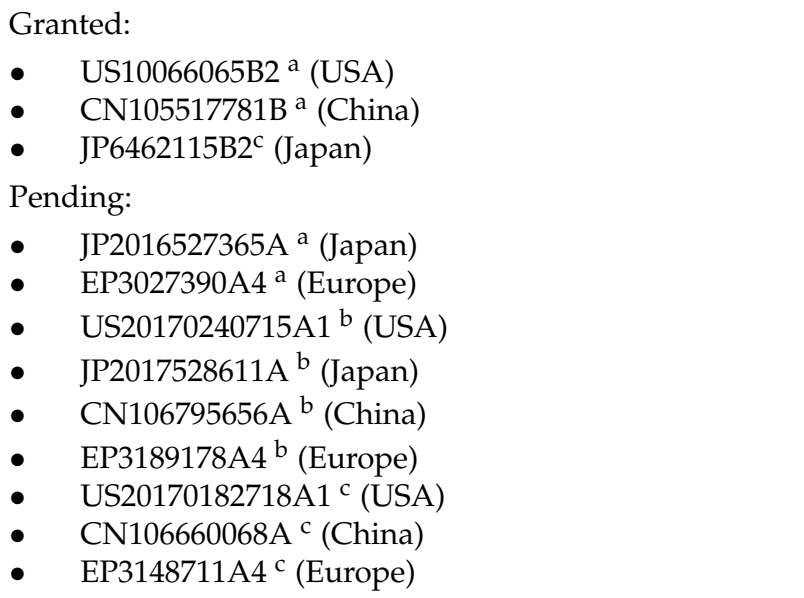 \\
\hline
\end{tabular}

Notes: TRL: Technology Readiness Level; PFI: Partnership for Innovation; STTR: Small Business Technology Transfer; SBIR: Small Business Innovation Research. ${ }^{a}$ Patent: Method for manufacturing nano-structurally aligned multi-scale composites [6]; ${ }^{b}$ Patent: Porous Nanocomposite and Related Method [37]; c Patent: Apparatus and method for directional alignment of nanofibers in a porous medium [38].

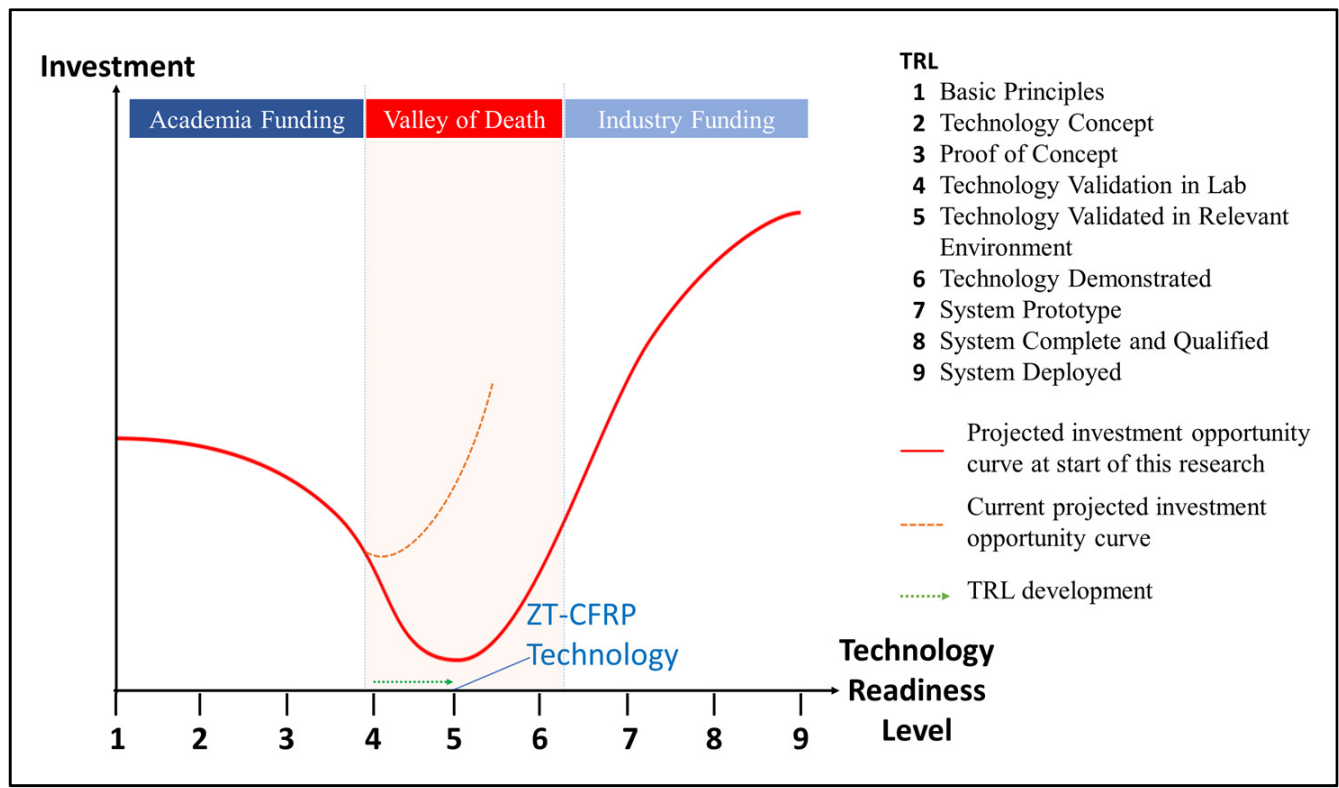

Figure 5. Updated investment vs. technology readiness level (TRL), showing the current projected investment opportunity curve and the TRL development of the ZT-CFRP technology. (Significantly modified and redrawn from original by Rossini [12]).

The comparison table shows how following the proposed commercialization framework clearly improved the chances of successful commercialization for the ZT-CFRP technology. This was achieved by reducing market and technological uncertainties, and therefore, the commercialization risk, by raising the willingness of potential customers to test the new technology, and by improving the technology's maturity level for additional funding possibilities. Throughout this process, the engineering analysis was an essential part of validating the value proposition, and therefore, of supporting the commercialization of the ZT-CFRP technology.

The proposed commercialization framework forms a system in which each analysis method plays an important role, and when combined, they lead to a strong commercialization strategy with validated value propositions that increases the chance of commercializa- 
tion for the technology. Figure 6 shows the difference between developing a business plan using the Lean LaunchPad approach and the new proposed commercialization framework. When using the Lean LaunchPad approach, a business plan is developed with the help of a business model canvas after performing a rigorous market analysis. Since this is not enough to commercialize a nanocomposite such as the ZT-CFRP technology, additional analyses are required to form a system of a market, system, and engineering analysis to develop a business plan. Only by combining the three analyses, it is possible to cover the market and technological uncertainties and to provide enough data to convince potential customers.

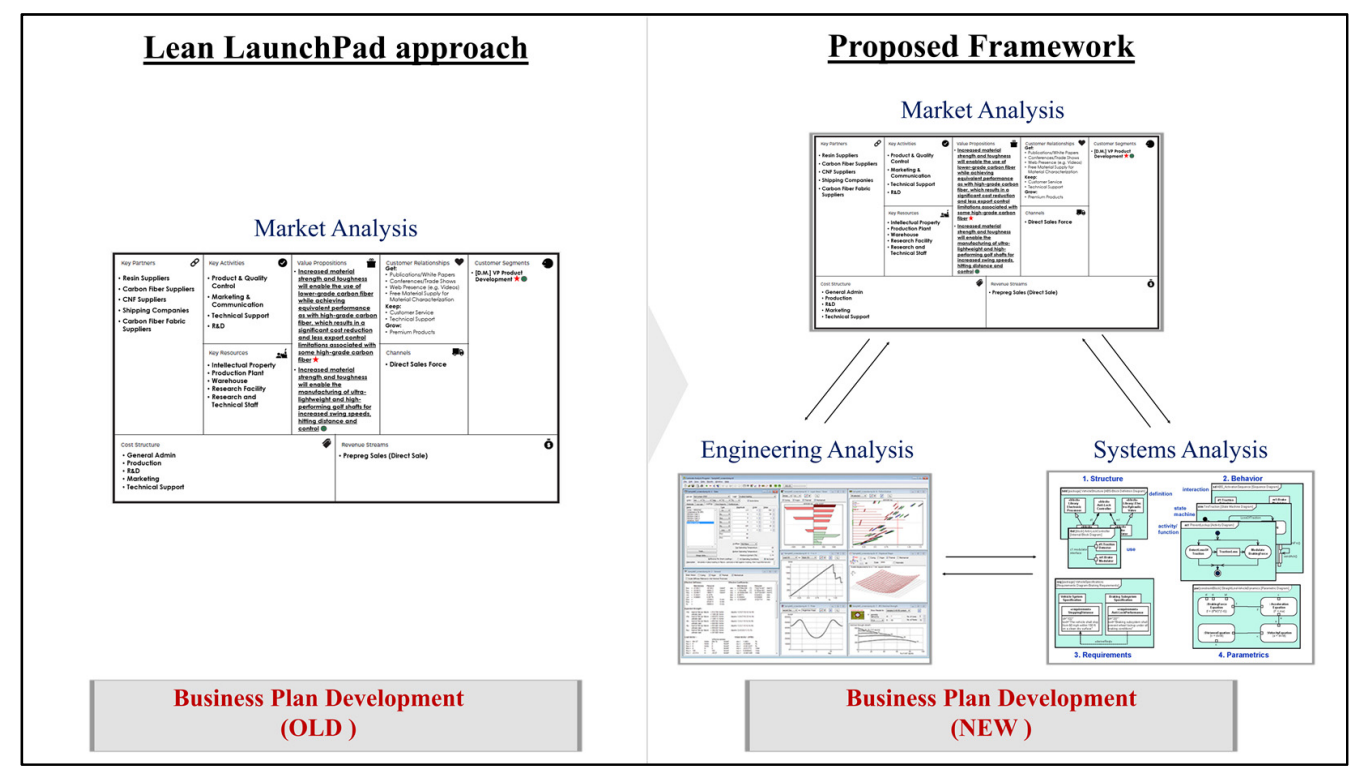

Figure 6. Comparison between developing a business plan using the Lean LaunchPad approach (old process on the left) and the proposed framework (new process on the right).

As shown in Table 2, this validates and supports the earlier stated propositions of a framework in which MBSE plays an important role when trying to overcome the many market and especially technological uncertainties that arise during the commercialization of nanocomposites. Furthermore, the information gained from the market analysis interviews validate the proposition of the importance that MBSE plays during the commercialization process. For example, during the interviews it became clear that a good and deep understanding of the product (i.e., the system) is necessary to convince potential customers. Moreover, MBSE supports the communication of difficult concepts during customer and stakeholder interactions.

The comparison of the commercialization status and technical readiness level (TRL) before and after utilizing the framework also validates and supports that this framework, which is a combination of the Lean LaunchPad approach, a Model-Based Systems Engineering methodology and a thorough engineering analysis, tremendously supports the commercialization process of nanocomposites such as the ZT-CFRP technology and, therefore, shortens the time to market, reduces costs and limits the risks. 
Table 2. Framework validation summary.

\begin{tabular}{cl}
\hline Propositions & \multicolumn{1}{c}{ Validation Criteria } \\
\hline $\begin{array}{c}\text { A framework in which MBSE plays an } \\
\text { important role when trying to overcome the } \\
\text { many market and especially technological } \\
\text { uncertainties that arise during the } \\
\text { commercialization of nanocomposites }\end{array}$ & $\bullet \quad \begin{array}{l}\text { Comparison of reduced uncertainties } \\
\text { (market and technology) } \\
\text { Improvement of chances for funding }\end{array}$ \\
$\begin{array}{c}\text { The proposed framework is a combination of } \\
\text { the Lean LaunchPad approach, a Model-Based } \\
\text { Systems Engineering methodology and a } \\
\text { thorough engineering analysis, which would } \\
\text { tremendously support the commercialization } \\
\text { process of nanocomposites such as the } \\
\begin{array}{c}\text { ZT-CFRP technology and, therefore, shorten } \\
\text { the time to market, reduce costs and limit } \\
\text { the risks. }\end{array}\end{array} \quad \begin{array}{l}\text { Comparison of the commercialization } \\
\text { status and technical readiness level (TRL) } \\
\text { before and after utilizing the framework }\end{array}$ \\
\hline
\end{tabular}

The framework requires multiple roles and responsibilities:

- A team lead that coordinates and overlooks the different analyses.

- A market analyst with background knowledge of the Lean LaunchPad approach that performs the market analysis (note that during the interviews, it is important that at least two people are present: one as the interview lead and question-asker, and one to take notes).

- A systems analyst with background knowledge in MBSE that performs the system analysis and develops the system architecture/model. A test engineer with deep background knowledge of the technology to develop a prototype and perform necessary tests.

Technically, one person could perform all analyses of the framework as long as he/she has a note-taker for the interviews. However, to use the proposed framework effectively, the authors suggest a group of people with enough knowledge of the individual analyses, as well as a team lead (e.g., a systems engineer). With a group of people, the individual analysis could be run in parallel and more efficiently. A culture should be created in which all involved parties have at least a basic understanding of the individual methods and the overall goal. For each analysis, an expert on the analysis and the technology should lead the team.

\section{Discussion}

\subsection{Compariosn between Lean LaunchPad Approach and the Proposed Framework}

The main difference between the two methods is that the Lean LaunchPad approach (which is a precursor of the Lean Startup method, LSM) focuses on identifying and overcoming market uncertainties by finding a successful business model, whereas the proposed framework combines the Lean LaunchPad approach with a systems analysis (MBSE methodology) and an engineering analysis. Such a symbiosis creates a comprehensive commercialization support structure that minimalizes not just market uncertainties, but also technological uncertainties, while providing a solid data structure to convince potential customer of a complex technology such as the ZT-CFRP technology.

The Lean LaunchPad analysis helps to analyze the market from the identification of viable value propositions all the way to the development of prizing, cost, and revenue strategies. However, this is just one part of the spectrum. Adding the systems analysis based on a MBSE methodology helps to identify and overcome technological uncertainties by developing a comprehensive system architecture model. The engineering analysis provides the necessary supporting data when approaching customers and convincing them of the technology's benefits and advantages over other technologies. The data gained from 
the engineering and systems analysis can then be fed into the market analysis (and vice versa) to further specify the analyses.

Now, we will consider the challenges and uncertainties that the ZT-CFRP technology will face and how the two methods are of value. For the commercialization challenges of the ZT-CFRP technology, the Lean LaunchPad will help to identify if the market is large enough and sufficiently profitable. It will also help with other market uncertainties such as the startup cost for the new venture, the ecosystem and cash flow, pricing tactics, etc. This will help to reduce many of the market uncertainties. The knowledge gained from this Lean LaunchPad analysis can also be used as, e.g., a starting point within the systems analysis, which will then help to reduce technological uncertainties.

For the identified marketing issue, a large amount of supporting data (e.g., material property data) are required, and the customer and system requirements have to be known. Here, the individual diagrams (e.g., the system domain for the inputs and especially output to the environment, and the context diagram for the environmental and human risk) from the system architecture can have great value. For example, these diagrams can be used to communicate with the customer to help to market the technology and to reduce their concerns (e.g., health and safety issues, and environmental effects). Moreover, partnerships between different entities will be needed to overcome some of the commercialization challenges of nanocomposites. This will require communication between many experts from different backgrounds. Being able to communicate complex issues effectively and graphically will definitely help to reduce communication barriers and, therefore, support the commercialization process. This shows how valuable the system architecture is within the proposed commercialization framework, which means that MBSE is an excellent supporting tool for the nanocomposite commercialization process.

In conclusion, while it is difficult to provide a quantitative result on how much better the proposed framework is compared to only using the Lean LaunchPad approach, it is clear that combining the market analysis of the Lean LaunchPad approach with a system and engineering analysis has clear benefits such as the reduction in uncertainties and an increased chance of receiving funding, as well as offering better way of marketing to potential customers. Such a symbioses of the three analyses provides a promising foundation for a strong commercialization strategy.

\subsection{Comparison to Other High Technology Commercialization Frameworks}

An extensive reference search for other commercialization frameworks for high or advanced technologies led to very few results. The authors could not find any articles that discuss in detail the utilization of MBSE for high technologies and advanced materials.

A framework, called the "Lean Commercialization Framework", which was developed by Gbadegeshin [39], provides detailed commercialization process steps that align with the core idea behind the proposed framework. While the lean commercialization framework focuses on the process, the proposed framework focuses more on the method and approaches. Another framework [40] for advanced technologies utilizes Life Cycle Assessment (LCA) results to support the commercialization process through the consideration of a technology's sustainability. However, the framework only focuses on the support of funding, which is just one aspect of the commercialization challenges for high technologies. In contrast, the proposed commercialization framework is comprehensive. By incorporating the proposed framework, it is possible to address the earlier mentioned three grand challenges for the commercialization of translational materials (Kordas [5]). As mentioned earlier, the results from the systems analysis can be used to improve communications and information exchange, and to even identify sustainability potential of the developed technology. Furthermore, since market and technological uncertainties are reduced, the chances for funding from, e.g., funding agencies are much higher than before. Moreover, the proposed framework addresses many of the internal constraining factors for commercialization of high technologies summarized in the review article by Daneshjoovash [41], which includes a review of 30 articles. Those include, e.g., market 
and product uncertainty, limited financial resources, and traditional marketing. However, while the proposed framework shows much promise, it also has its limitations. Those limitations are discussed in the following sub-section.

\subsection{Limitations of the Proposed Framework}

The proposed framework is based on a case study research methodology, which at first can constrain a direct generalization of the framework for non-similar technologies. However, it provides a base and could be adapted easily for other advanced-material technologies since all of them have similar challenges and uncertainties, as discussed by Maine and Seegopaul [18]. Moreover, the framework was developed in the context of the United States markets.

Applying this framework in other countries will need the consideration of regional factors such as funding opportunities and existing funding systems, the availability of a qualified workforce, regulations and incentives for new inventions and startups, the local market ecosystem, as well as available technology resources. For example, funding opportunities and other factors may be different depending on the country in which the technology commercialization market effort is being pursued. Funding opportunities and support by the government vary from country to country, or even partially from state to state within the United States. Environmental consciousness that varies by region and country will also be a factor during the commercialization process. Additionally, different regulations for the use or the system's end-of-life may exist. While those could be limiting factors for the technology's commercialization, when applied effectively, the framework will help understand those reginal factors by providing necessary market and technological understanding to tackle them.

Internal organizational factors need to be considered as well when applying the proposed framework. For example, as mentioned earlier, the inclusion of a group of people with enough understanding of the individual analysis methods is recommended to effectively implement the proposed framework. Moreover, commercialization requires flexibility for pivoting and an error acceptance culture. Therefore, the organizational internal structure has to provide enough freedom and resources for the individuals.

Lastly, the technology on which the case study is based is not yet fully commercialized, and the framework has not been applied to other similar technologies. Therefore, the validation of this framework is constrained to the limited available data.

\subsection{A MBSE Model for the Proposed Framework}

As shown for the systems analysis, MBSE can be a powerful tool during the commercialization process of nanocomposites. Using MBSE and one of the SysML software tools (e.g., the Cameo Systems Modeler from No Magic, Rational Rhapsody from IBM, Enterprise Architect from Sparx Systems, or Astah SysML from Astah.net), it is possible to implement the whole framework into one comprehensive model by integrating and modeling the results of the market analysis to link those results with the results from the engineering analysis and the system model using SysML.

One difficulty during the commercialization process of nanocomposites (such as CFRPs reinforced with nanoparticles) is that each customer requires their own unique material system (i.e., a combination of a resin system and carbon fiber material). Using the MBSE model can help to identify quickly (upfront) if this new customer is economical in terms of price point and material performance. For this, the analytical model, as shown in one of the research articles [10], which helps to predict the interlaminar shear strength of the ZT-CFRP, could be implemented into the ZT-CFRP architecture (using, e.g., MATLAB). This could then be used when, for example, a new customer has a specific material requirement (e.g., a specific ILSS). The architecture could then be updated with new raw material properties, and the model would predict the new ILSS of the ZT-CFRP and determine if it satisfies the new requirements set by the customer. At the same time, the architecture would run an analysis to determine if the new raw materials provide enough profit due to 
the linkage between the amount the customer is willing to pay and the COGs. Such a model could partially automate the commercialization process by running multiple analyses in one model and validating several requirements at once.

\section{Conclusions}

The framework developed in this research is a combination of the Lean Launchpad Method, a Model-Based Systems Engineering methodology and a thorough engineering analysis. It helps to build a deeper understanding of the complexity of the commercialization process. Furthermore, while it proved useful in advancing academic research and could also be of help to industry experts during R\&D (research and development) transformation by overcoming some of the main hurdles of the nanocomposites' commercialization process, as other researchers adopt this approach, it may lead to more nanocomposite technologies making it out of the development stage, into the industry, and into the consumer's hands. Therefore, material scientists would be able to accommodate the society's needs for better-performing products and systems, and thus, make the currently impossible possible. Moreover, the framework is intended to assist advanced material-based companies, material scientists, researchers and entrepreneurs during the commercialization process by minimizing uncertainties and risks, while focusing resources to reduce time-to-market and development costs.

Future work should be focused on expanding the MBSE model, which could even be developed into a tool/software that could be directly adapted by entrepreneurs and scientists to support their commercialization process. Furthermore, additional validating case studies should be performed with other nanocomposite technologies or even other high technologies. The implementation of a life cycle analysis could also be beneficial in terms of increased identification of environmental effects.

Author Contributions: Conceptualization, S.K.; methodology, S.K.; validation, S.K., R.J.C. and K.T.H.; formal analysis, S.K.; investigation, S.K. and K.-T.H.; resources, R.J.C. and K.-T.H.; data curation, S.K.; writing —original draft preparation, S.K.; writing—review and editing, S.K., R.J.C. and K.-T.H.; visualization, S.K.; supervision, K.-T.H.; project administration, S.K. and K.-T.H.; funding acquisition, S.K., R.J.C. and K.-T.H. All authors have read and agreed to the published version of the manuscript.

Funding: This research was funded by the NATIONAL SCIENCE FOUNDATION (National Innovation Corps (I-Corps) Teams Program; award number: 1748369), and the Graduate Assistantship from the Systems Engineering Program and Graduate School at the UNIVERSITY OF SOUTH ALABAMA.

Institutional Review Board Statement: Not applicable.

Informed Consent Statement: Not applicable.

Data Availability Statement: Data supporting the reported results is contained within the main body of the article and the Appendices A-C. Detailed market, system and engineering analysis data can be found in the dissertation published by Sebastian Kirmse at the University of South Alabama [32] or cannot be made available due to confidentiality reasons.

Acknowledgments: The authors would like to acknowledge the financial support of the National Science Foundation (National Innovation Corps (I-Corps) Teams Program—award number: 1748369), and the Graduate Assistantship from the Systems Engineering Program and Graduate School at the University of South Alabama. Moreover, the authors would like to thank Michael Chambers and Anh-Vu Phan for their inputs and suggestions during this research study. 
Conflicts of Interest: The manufacturing method for the CNF z-threaded CFRP prepreg is disclosed in the patent application titled "Method for manufacturing nanostructurally aligned multiscale composites" (WO2015017321 A1 (first published on Feb 5, 2015), CN 105517781 B, CN105517781A, EP3027390A1, EP3027390A4, and US20160168342); this manufacturing method was invented by Kuang-Ting Hsiao and Gregory Hickman. The ZT-CFRP technology is currently funded under the National Science Foundation (NSF) Award \#2044513 PFI-TT: “High-Volume Manufacturing of Next Generation Carbon Reinforced Pre-Impregnated Polymer Composites", with Kuang-Ting Hsiao and Michael Chambers as principal investigators and Sebastian Kirmse as an outside consultant, to further the commercialization of the technology.

Disclosure: The work presented within this article is based on the dissertation published by Sebastian Kirmse at the University of South Alabama [32].

\section{Appendix A}

A sample questionnaire that the authors used during their interviews is included in Table A1 to provide further details about the data-collection process.

Table A1. General sample questionnaire used during the performed interviews.

\begin{tabular}{cc}
\hline Interview Question & Answer/Notes \\
\hline What is your name, job title and affiliation? & \\
\hline How long have you been working in your current position? &
\end{tabular}

Do you have direct decision power over the integration of new materials in a product?

What kind of products does your company produce?

What challenges do you have with your current materials?

How does the general ecosystem look within your industry and where is your organization positioned within the value chain?

What properties are you usually looking for in a new material?

What kinds of properties would the ideal material have?

How do you become informed about new technology invention and how do you evaluate them?

How critical is the price point of a new material?

Have you had any kind of experience with nanotechnologies/-materials?

Are you using prepreg materials?

How much prepreg/material are you generally using for your products?

What is your production speed?

Do you or your suppliers have to comply to any regulations?

How long is your product development time?

How conservative is your industry for new inventions?

What are general quality control requirements for your suppliers?

Note: The interviews were performed without any non-disclosure agreement. As needed, the interviewees were asked to generalize the answers to ensure confidentiality.

\section{Appendix B}

A summary of interview results based on industry is provided below.

Sporting goods industry:

For the sporting goods industry, the focus should lay on the golf shaft market segment. Here, the customer segment was defined as upper-level management of product development (e.g., Vice President (VP) of Product Development) within organizations that manufacture carbon fiber (i.e., graphite) golf shafts.

The identified value propositions are: 
- Increased material strength and toughness will enable the use of lower-grade carbon fiber while achieving equivalent performance to that of high-grade carbon fiber, which results in a significant cost reduction and less export control limitations associated with some high-grade carbon fiber.

- Increased material strength will enable the manufacturing of ultra-lightweight, highperforming golf shafts for increased swing speed, hitting distance, and control.

The sporting goods industry is a brand builder but not a volume driver. Within this industry, customers have a high willingness to pay for premium products and product development times are just 1-2 years. However, while the golf shaft market is one of the largest markets for advanced composite material within the sporting goods industry, compared to the aerospace or automotive industry, its volume is much lower, which therefore limits wide-scale adoption within the golf shaft segment and will require expansion towards other customer segments such as the aircraft segment.

Aerospace industry:

For the aerospace industry, the focus should lay on the commercial aircraft market segment. Here, the customer segment is defined as upper-level management and engineers at aircraft manufacturers and Tier 1 suppliers that use prepreg to manufacture components and parts.

The identified value propositions are:

- $\quad$ Structural weight savings of $20 \%$ reduce operational costs by $\sim 10 \%$.

- Improvements of 50\% in ILSS reduce repair costs of structural composites by $20 \%$.

- $\quad$ Removing metal mesh reduces airplane weight by $454 \mathrm{~kg}$ (1000 lbs.).

Moreover, these value propositions are based on the major findings found during the interviews with potential customers in this industry. Those major findings were:

- Currently, metal meshes are used for composite parts for lightning strike protection, which adds additional weight to the aircraft.

- $\quad$ There is a large need for weight reduction in aircraft for competitive advantages.

- The repair cost for composite parts on aircraft is very high due to the long repair time, which results in long downtimes for the aircraft.

- $\quad$ Being able to eliminate the metal mesh (454 kg) for an A320 aircraft could save USD 430,000 in fuel savings per service life (30 years) of an aircraft at a jet fuel cost of USD 1.91 /gallon, with the assumption that " $100 \mathrm{~kg}$ of excess weight requires an additional $5000 \mathrm{~kg}$ of fuel per year per aircraft" (p.13) [42]. Based on a list price of USD 101.0 million [43], this would be a saving of over $4 \%$.

The aerospace industry is a very high-volume market. However, the customer segmentation for the commercial aircraft market segment is much more complex than it is for the golf shaft market segment. There are lots of different influencers for the adoption of new materials, such as Tier 1 and Tier 2 suppliers, aircraft OEMs, and even the airline. The material venture's positioning within the commercial aircraft value chain is anything but optimal. Another issue for wide-scale adoption in the aircraft segment is the long adoption time due to long certification processes, which are required since human lives are at risk. The Federal Aviation Administration (FAA) requires certifications for composite materials used in aircraft, which require lots of testing and strict quality control measures. It is very difficult to live up to such high-quality standards set by the FAA for aircraft components. Therefore, the development process can take many years (5-15 years) and high upfront investments (USD 2 Million to 20 Million).

Automotive industry:

For the automotive industry, the focus should lay on the luxury, high-performing vehicle segment. Here, the customer segment was defined as VP of product development and materials engineers within organizations that produce low-volume, lightweight and high-performing cars as well as electric vehicles

The identified value proposition is: 
- Increased material strength together with improved electrical and thermal conductivity will enable improved applications that result in lower vehicle weight and, therefore, lower fuel/energy consumption.

The automotive industry market is very time sensitive with strong competition in terms of steel and alloy products. The ecosystem can be complex with different regulations and high-quality control requirements. The production speed is very quick, which could make the adoption of prepreg materials challenging. The security of supply chain and recycling provide additional challenges for material ventures. The overall market volume for lightweight materials is fairly large and has been growing significantly in recent years due to the need to lower vehicle weights in order to increase the range for electric vehicles. Moreover, the production time of $2-4$ years is much lower than for the aerospace industry.

\section{Appendix C}

The prepreg will be used by golf shaft manufacturers to produce high-end carbon fiber golf shafts with high quality and outstanding performance. The prepreg will be produced by an automated production machine, rolled up and stored, and then shipped to the golf shaft manufacturer. The shipping and storage condition will be dry and at a low temperature (under $10^{\circ} \mathrm{C}$ ). At the manufacturer's site, the prepreg will continue to be stored until it is used for the golf shaft manufacturing. The prepreg will be used to manufacture high-end, high-performing golf shafts. The material has to be safe for humans and the environment during handling and once it is manufactured into a golf shaft. Furthermore, the golf shaft manufacturer has specific dimensional requirements (usually defined in a stakeholder requirement list). For better representation, the CONOPS was modeled in an activity diagram, as shown in Figure A1, which helps to understand the CONOPS description better.

A context diagram was developed, which defines the system of interest, its scope, its boundary, and its interactions with the critical elements in its environment. Figure A2 shows the context diagram for the ZT-CFRP prepreg developed in PowerPoint.

The ZT-CFRP prepreg system domain is defined in the system domain diagram shown in Figure A3, which captures all of the systems, people, and other entities that interact with the system of interest, directly or indirectly. Domain diagrams are usually used to set a common understanding of the scope of a modeling effort, to establish a common vocabulary, to reason about the problem space, and to help identify system interfaces and boundaries.

The stakeholders identified for the system of interest were divided into active and passive stakeholders and modeled in a use case diagram (see Figure A4). Active stakeholders are individuals, entities, and other systems, which will actively interact with the system of interest once it is operational and in use. Passive stakeholders are individuals, entities, other systems, standards, protocols, procedures, and regulations, which will also influence the 'success' of the system. 


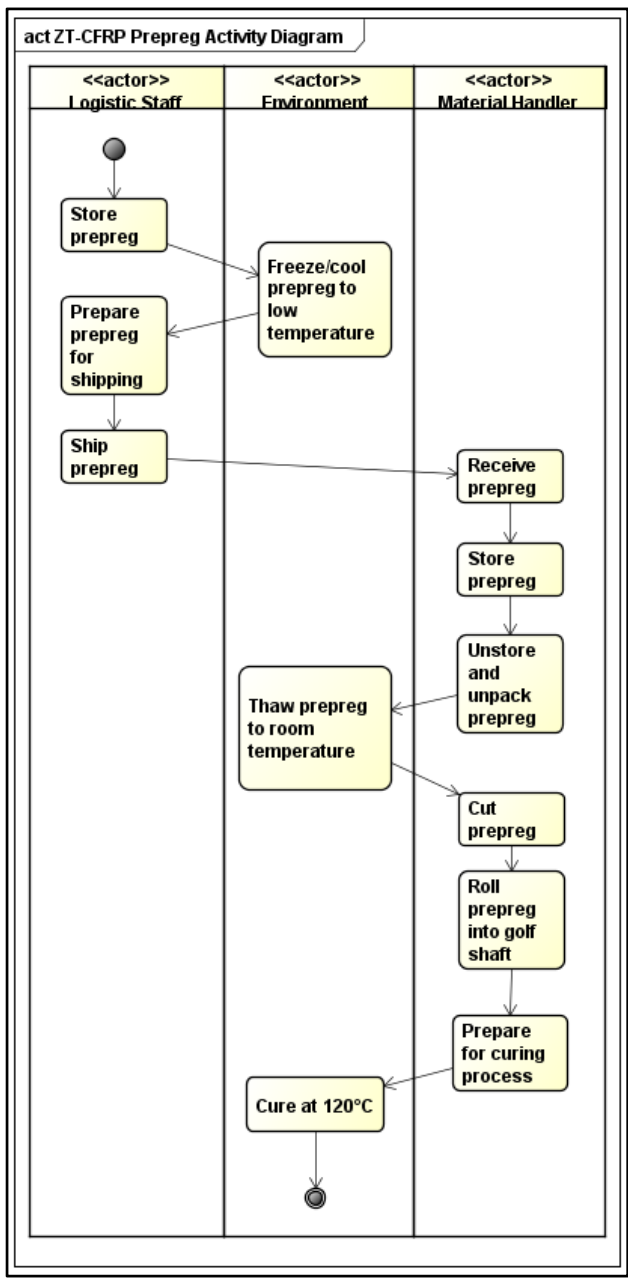

Figure A1. CONOPS for the ZT-CFRP presented in an activity diagram.

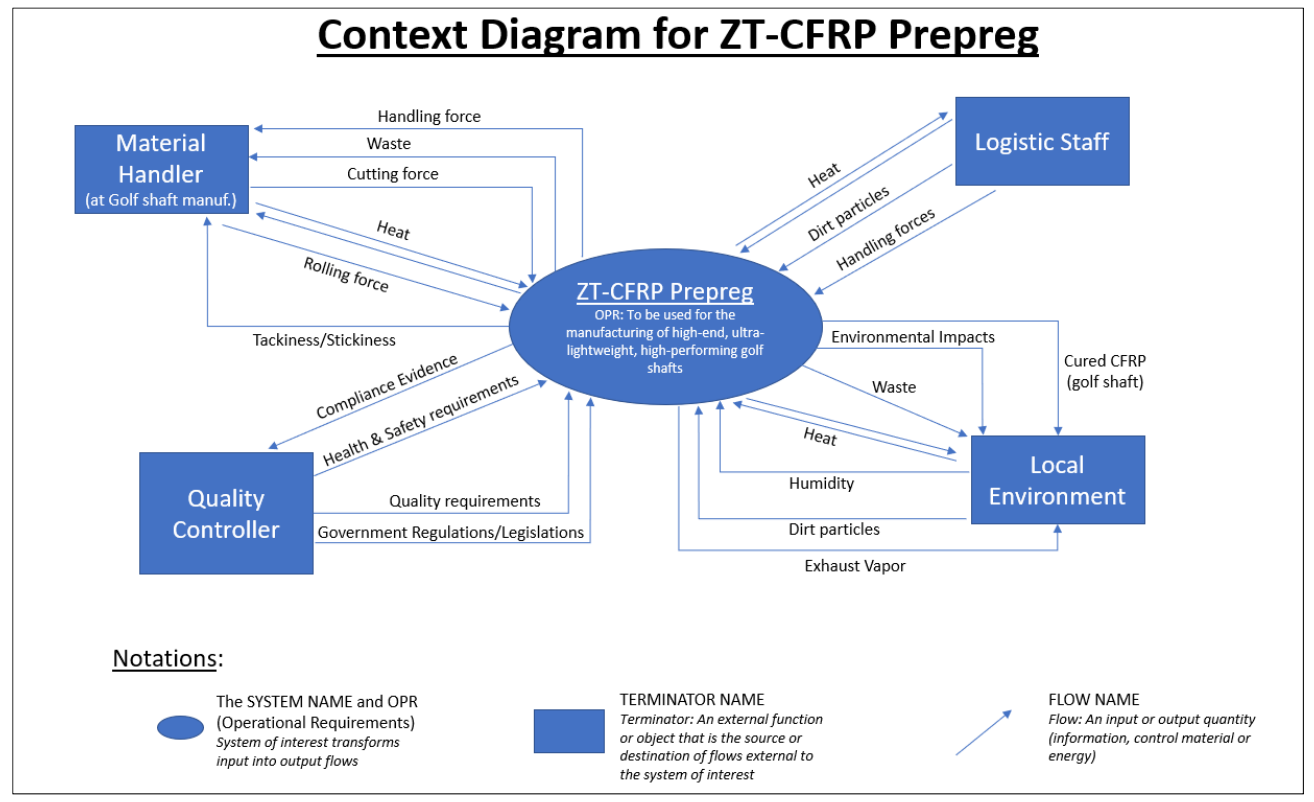

Figure A2. Context diagram for the ZT-CFRP prepreg (developed in PowerPoint). 


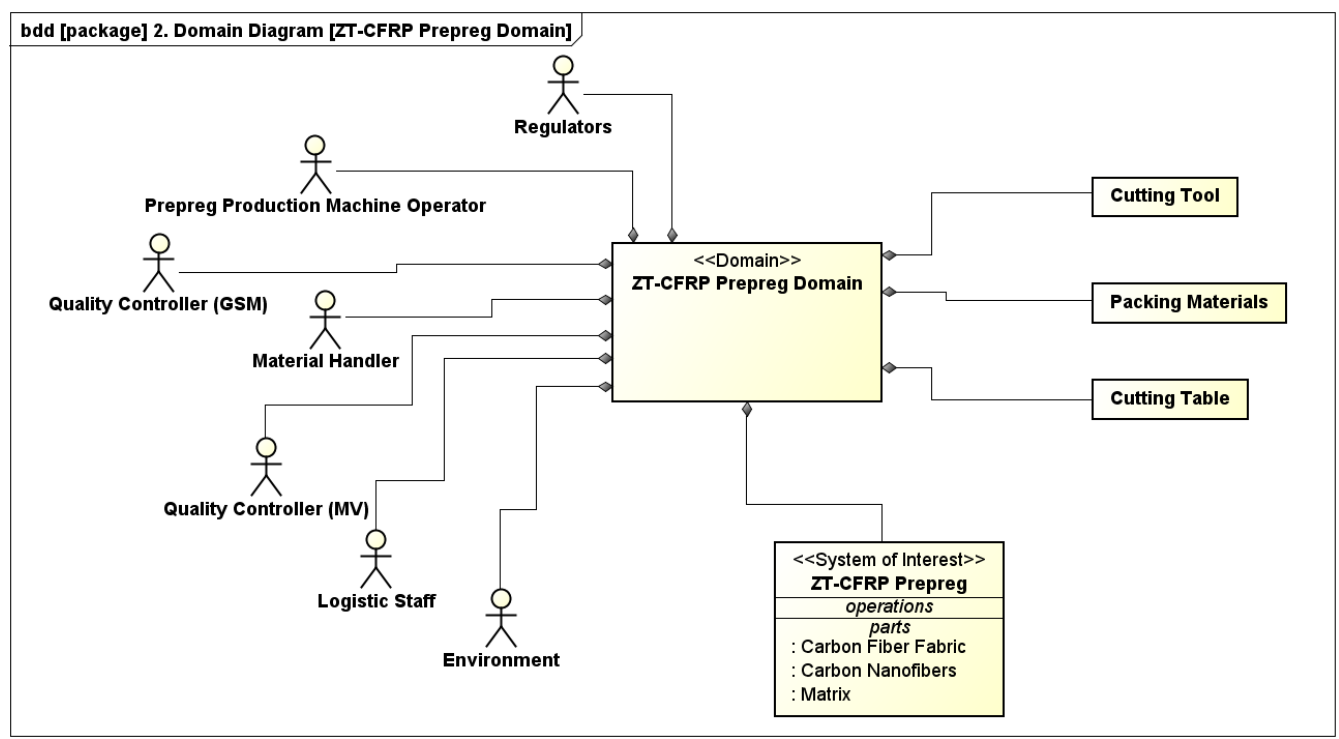

Figure A3. Domain diagram for the ZT-CFRP prepreg system domain.

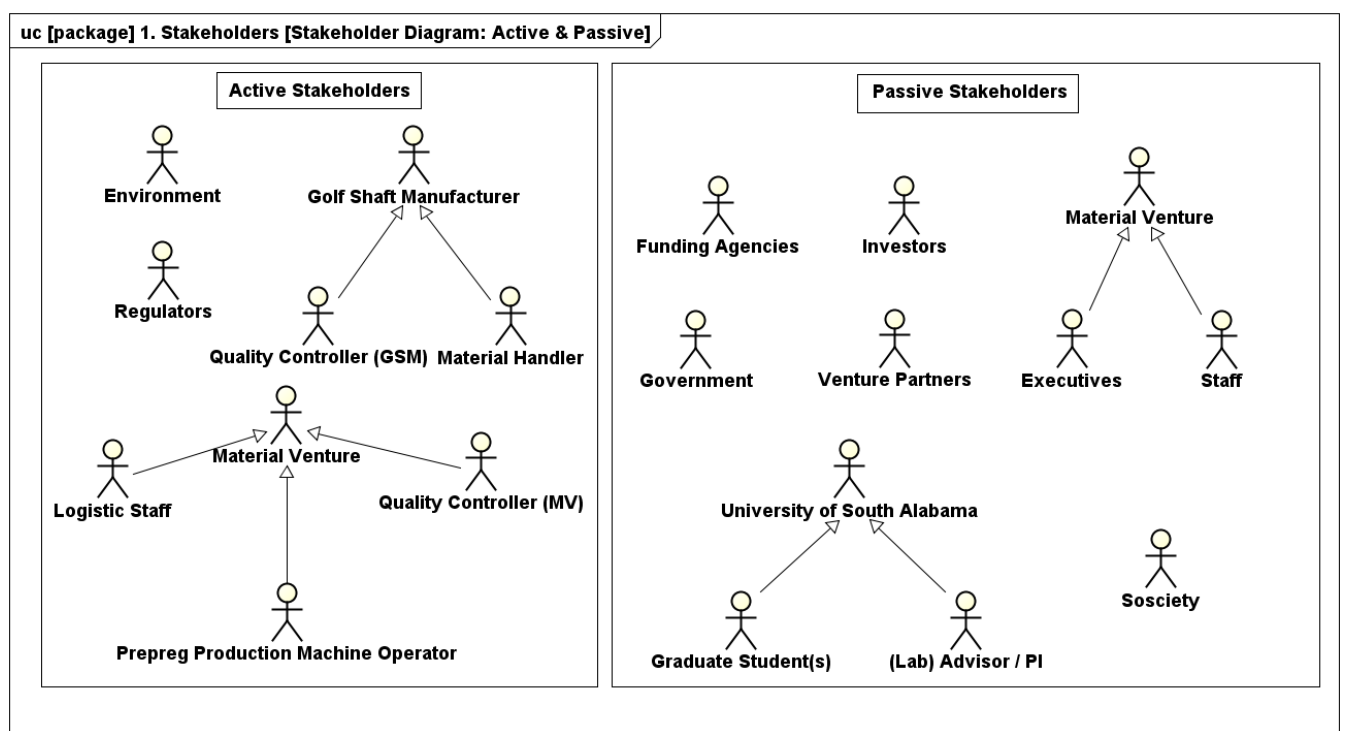

Figure A4. Active and passive stakeholder diagram, where MV stands for material venture.

\section{References}

1. AlOmari, A.S.; Al-Athel, K.S.; Arif, A.F.M.; Al-Sulaiman, F.A. Experimental and Computational Analysis of Low-Velocity Impact on Carbon-, Glass- and Mixed-Fiber Composite Plates. J. Compos. Sci. 2020, 4, 148. [CrossRef]

2. Kandare, E.; Khatibi, A.A.; Yoo, S.; Wang, R.; Ma, J.; Olivier, P.; Gleizes, N.; Wang, C.H. Improving the through-thickness thermal and electrical conductivity of carbon fibre/epoxy laminates by exploiting synergy between graphene and silver nano-inclusions. Compos. Part A Appl. Sci. Manuf. 2015, 69, 72-82. [CrossRef]

3. Rider, A.N. 6.12 Hierarchical Nanocomposites/Multi-Scale Composites. In Comprehensive Composite Materials II; Beaumont, P.W.R., Zweben, C.H., Eds.; Elsevier: Oxford, UK, 2018; pp. 352-379.

4. Spitalsky, Z.; Tasis, D.; Papagelis, K.; Galiotis, C. Carbon nanotube-polymer composites: Chemistry, processing, mechanical and electrical properties. Prog. Polym. Sci. 2010, 35, 357-401. [CrossRef]

5. Kordas, K. Grand Challenges in Translational Materials Research. Front. Mater. 2017, 4, 38. [CrossRef]

6. Hsiao, K.-T.; Hickman, G. Method for Manufacturing Nano-Structurally Aligned Multi-Scale Composites. WO/2015/017321, 5 February 2015. 
7. Kirmse, S.; Hsiao, K.-T. Enhancing the Interlaminar Shear Strength of Unidirectional Carbon Fiber Reinforced Plastic (CFRP) Laminate Using a Nanofiber Z-Threading Strategy. In Proceedings of the Composites and Advanced Materials Expo (CAMX) 2018, Dallas, TX, USA, 15-18 October 2018. TP18-0499.

8. Scruggs, A.M.; Kirmse, S.; Hsiao, K.-T. Enhancement of Through-Thickness Thermal Transport in Unidirectional Carbon Fiber Reinforced Plastic Laminates due to the Synergetic Role of Carbon Nanofiber Z-Threads. J. Nanomater. 2019, 2019, 8928917. [CrossRef]

9. Kirmse, S. Interlaminar Shear Strength Enhancement of Unidirectional Carbon Fiber Reinforced Plastic Laminates Using a Carbon Nanofiber Z-Threading Technique. Master's Thesis, University of South Alabama, Mobile, AL, USA, July 2018.

10. Kirmse, S.; Ranabhat, B.; Hsiao, K.-T. Experimental and analytical investigation on the interlaminar shear strength of carbon fiber composites reinforced with carbon nanofiber z-threads. Mater. Today Commun. 2020, 25, 101512. [CrossRef]

11. Scruggs, A.M.; Henderson, K.; Hsiao, K.-T. Characterization of Electrical Conductivity of a Carbon Fiber Reinforced Plastic Laminate Reinforced With Z-Aligned Carbon Nanofibers. In Proceedings of the Composites and Advanced Materials Expo (CAMX) 2016, Anaheim, CA, USA, 26-29 September 2016. TP16-0137.

12. Rossini, A. Bridging the Technological "Valley of Death". Available online: https://www.pwc.no/en/bridging-the-technologicalvalley-of-death.html (accessed on 19 August 2021).

13. Mai, T. Technology Readiness Level. Available online: https://www.nasa.gov/directorates/heo/scan/engineering/technology/ txt_accordion1.html (accessed on 19 August 2021).

14. The National Science Foundation's Innovation Corps (I-Corps $\left.{ }^{\mathrm{TM}}\right)$. Available online: https://www.nsf.gov/news/special_reports / i-corps / (accessed on 19 August 2021).

15. Blank, S. Steve Blank Startup Tools. Available online: https:/ / steveblank.com/ (accessed on 19 August 2021).

16. Ries, E. The Lean Startup: How Today's Entrepreneurs Use Continuous Innovation to Create Radically Successful Businesses; Crown Business: New York, NY, USA, 2011.

17. Harms, R.; Marinakis, Y.; Walsh, S.T. Lean startup for materials ventures and other science-based ventures: Under what conditions is it useful? Transl. Mater. Res. 2015, 2, 035001. [CrossRef]

18. Maine, E.; Seegopaul, P. Accelerating advanced-materials commercialization. Nat. Mater. 2016, 15, 487-491. [CrossRef] [PubMed]

19. Liu, D. Systems Engineering: System Design Principles and Models; CRC Press: Boca Raton, FL, USA, 2016.

20. Hart, L.E. Introduction to Model-Based System Engineering (MBSE) and SysML. In Proceedings of the Delaware Valley INCOSE Chapter Meeting, Mt. Laurel, NJ, USA, 30 July 2015.

21. INCOSE UK, Why MBSE? (Z9). Issue 1.0. January 2012. Available online: https://www.yumpu.com/en/document/view/3281 7438/open-incose-uk-chapter (accessed on 16 November 2021).

22. Denzin, N.K.; Lincoln, Y.S. The SAGE Handbook of Qualitative Research, 4th ed.; SAGE Publications, Inc.: Thousand Oaks, CA, USA, 2011.

23. Kirmse, S.; Kim, K.; Ranabhat, B.; Hsiao, K.-T. Effects of Carbon Nanofiber Z-Threads on the Longitudinal Compressive Strength of Unidirectional CFRP Laminates. In Proceedings of the Society for the Advancement of Material and Process Engineering (SAMPE) 2019, Charlotte, NC, USA, 20-23 May 2019. TP19-1531.

24. Osterwalder, A.; Pigneur, Y. Business Model Generation; John Wiley \& Sons, Inc.: Chichester, UK, 2010.

25. Osterwalder, A.; Pigneur, Y.; Bernarda, G.; Smith, A. Value Proposition Design; John Wiley \& Sons, Inc.: New York, NY, USA, 2014.

26. Blank, S.; Dorf, B. The Startup Owner's Manual: The Step-by-Step Guide for Building a Great Company, 1st ed.; K\&S Ranch Inc.: Pescadero, CA, USA, 2012.

27. INCOSE Technical Operations. INCOSE Systems Engineering Vision 2020; INCOSE-TP-2004-004-02, Version 2.03; International Council on Systems Engineering (INCOSE): San Diego, CA, USA, 2007.

28. Weilkiens, T.; Lamm, J.G.; Roth, S.; Walker, M. Model-Based System Architecture; John Wiley \& Sons, Inc.: Hoboken, NJ, USA, November 2015.

29. Cloutier, R.J. Module 5/6: Modeling with SysML. Lecture in SE 606: Systems Architecture and Modeling. 2019; [PowerPoint Presentation].

30. Reed Integration Inc. CSEP Exam Success Sheet; Reed, B., Ed.; Reed Integration, Inc.: Suffolk, VA, USA, 2016; ASIN: B003AKSVDA. Available online: https:/ /www.amazon.com/CSEP-Exam-Success-Sheet-Integration/dp/B003AKSVDA (accessed on 16 November 2021).

31. Kirmse, S.; Ranabhat, B.; Hsiao, K.-T. A Preliminary Study of the Electrical and Interlaminar Shear Properties of a Porous CFRP Composite Laminate Containing Carbon Nanofiber Z-Threads. In Proceedings of the Composites and Advanced Materials Expo (CAMX) 2019, Anaheim, CA, USA, 23-26 September 2019. TP19-0773.

32. Kirmse, S. Towards the Commercialization of a Carbon Fiber Composite Reinforced with Carbon Nanofiber Z Threads Utilizing a Hybrid Lean LaunchPad/Model-Based Systems Engineering Approach. Ph.D. Thesis, University of South Alabama, Mobile, AL, USA, December 2019.

33. Hsiao, K.-T.; Scruggs, A.M.; Brewer, J.S.; Hickman, G.J.S.; McDonald, E.E.; Henderson, K. Effect of carbon nanofiber z-threads on mode-I delamination toughness of carbon fiber reinforced plastic laminates. Compos. Part A Appl. Sci. Manuf. 2016, 91, 324-335. [CrossRef]

34. Scruggs, A.M. Enhancement of Through-Thickness Electrical Conductivity Due to Carbon Nanofiber Z-Threads in Unidirectional Carbon Fiber Reinforced Plastic Laminates. Master's Thesis, University of South Alabama, Mobile, AL, USA, May 2018. 
35. Bayat, F.; Hsiao, K.-T. Mechanical behavior modeling of unidirectional carbon fiber reinforced polymer composites reinforced with z-directional nanofibers. In Proceedings of the Society for the Advancement of Material and Process Engineering (SAMPE) 2018, Long Beach, CA, USA, 21-24 May 2018. SE18-1101.

36. Kim, K.; Hsiao, K.-T. Modeling Transversal Support from Nanofiber Z-Threads to a Carbon Fiber by Finite Element Analysis of a CFRP Unit Cell. In Proceedings of the Composites and Advanced Materials Expo (CAMX) 2019, Anaheim, CA, USA, 23-26 September 2019. TP19-0859.

37. Hsiao, K.-T. Porous Nanocomposite and Related Method. WO2018175936A1, 23 March 2018.

38. Hsiao, K.-T. Apparatus and Method for Directional Alignment of Nanofibers in a Porous Medium. WO2015/184151, 11 February 2020.

39. Gbadegeshin, S.A. Lean Commercialization: A New Framework for Commercializing High Technologies. Technol. Innov. Manag. Rev. 2018, 8, 50-63. [CrossRef]

40. Upadhyayula, V.K.K.; Gadhamshetty, V.; Shanmugam, K.; Souihi, N.; Tysklind, M. Advancing game changing academic research concepts to commercialization: A Life Cycle Assessment (LCA) based sustainability framework for making informed decisions in Technology Valley of Death (TVD). Resour. Conserv. Recycl. 2018, 133, 404-416. [CrossRef]

41. Daneshjoovash, S.K.; Jafari, P.; Khamseh, A. Effective commercialization of high-technology entrepreneurial ideas: A metasynthetic exploration of the literature. J. Small Bus. Entrep. 2021, 33, 663-688. [CrossRef]

42. Getting to Grips with Fuel Economy. Airbus-Flight Operations Support \& Line Assistance, Issue 4, October 2004. Available online: https: / / ansperformance.eu/library / airbus-fuel-economy.pdf (accessed on 16 November 2021).

43. Airbus Aircraft 2018 Average List Price* (USD Millions). Airbus Press Office. Available online: https://web.archive.org/web/ 20180115185203/http:/www.airbus.com/content/dam/corporate-topics/publications/backgrounders / Airbus-CommercialAircraft-list-prices-2018.pdf (accessed on 16 November 2021). 